Article

\title{
Frenulectomy with Diode Laser Technology in Paeditric Patients: Quantitative and Qualitative Evaluations. Randomized Double- Blind Clinical Trial
}

\author{
Gian Luca Sfasciotti, Francesca Zara *(D), Miriam Fioravanti, Mariana Guaragna, Gaspare Palaia \\ and Antonella Polimeni $\mathbb{D}$ \\ Department of Oral and Maxillo-Facial Sciences, Sapienza University of Rome, 00161 Rome, Italy; \\ gianluca.sfasciotti@uniroma1.it (G.L.S.); miriam.fioravanti@uniroma1.it (M.F.); \\ mariana.guaragna@uniroma1.it (M.G.); gaspare.palaia@uniroma1.it (G.P.); \\ antonella.polimeni@uniroma1.it (A.P.) \\ * Correspondence: zarafrancesca94@gmail.com
}

Received: 26 May 2020; Accepted: 13 June 2020; Published: 15 June 2020

\begin{abstract}
Background: Ankyloglossia is an anatomical alteration of the frenulum length, volume, compactness, and insertion. It can lead to alterations in the ability to swallow and chewing, and dysfunctional coordination amongst cranio-facial muscles; these alterations are often responsible for respiratory alterations, skeletal malocclusions and dyslalia or the delay of speech. The aim of this study is to estimate the efficacy of lingual frenulectomy with diode-laser technology through a qualitative and quantitative evaluation. Methods: One hundred and twenty-five pediatric patients were recruited: 100 with a lingual pathological frenulum were randomly divided into four operating groups; the other 25 with a borderline pathological frenulum were recruited as a control group. Each patient was included in a follow-up program (T0-T1-T2-T3-T4) for a quantitative and qualitative evaluation: the first through an accurate measurement of Kotlow's free tongue measurement $(\geq 16)$, Mouth Opening with Tongue Tip to incisive papilla (MOTTIP), Maximal Intercisal Mouth Opening (MIO) and Protrusion; and the second using the Assessment Tool for Lingual Frenulum Function (ATLFF), Bristol Tongue Assessment Tool (BTAT), and grade of tongue functionality. Results: The increase of the aforementioned quantitative parameters was circa $10 \mathrm{~mm}$, and all patients reacquired full functionality of the tongue. Conclusions: Diode-laser technology is efficient and innovative in the treatment of pathological lingual frenulums.
\end{abstract}

Keywords: ankyloglossia; frenulectomy; tongue-tie; lingual frenulum; laser; diode laser; laser therapy; oral surgery; paediatric

\section{Introduction}

The lingual frenulum is formed from the oral mucosa and connective tissues within 22 weeks of gestation; at the time of its formation, any alteration of embryological processes could cause changes in its anatomical structure [1]. The anatomy of the lingual frenulum is poorly described in textbooks (Sinnatamby and Last [2]; Standring [3]); however, a recent study illustrated how it develops from concurrent muscular and mucous components [4]. Currently, there are no publications providing relevant additional details on the physiological morphology. Therefore, it is hard to understand how pathological variables can determine functional limitations of the tongue in children and young patients [5]. Important consequences of the functional limitation of the tongue can occur both in new-borns and during growth. e.g., breastfeeding, breathing complications, the phenomenon 
of asphyxiation, and food rejection [6-8] are common in the former group; in the latter, typical consequences are dyslalia and the delay of speech [9-11]. The functional limitations produce changes in swallowing and chewing, preventing the correct coordination of muscles, leading to a number of problems, e.g., cleft palate and cleft lip [12,13], oral respiration [14] and forward tongue positioning with possible malocclusions $[15,16]$. Therefore, different medical professionals (pediatrician, oral surgeon, orthodontist and speech therapist) are required to treat this condition, which has a prevalence rate of $4 \%$ to $10 \%$ [17] among infants, with a ratio between male and female of 2:1 [18]; ethnicity is not a risk factor $[7,19]$. The diagnosis of the pathological lingual frenulum is challenging, requiring the use of different parameters. There are both qualitative scales (Assessment Tool for Lingual Frenulum Function ATLFF [20], Bristol Tongue Assessment Tool BTAT [21], grade of tongue's functionality [22]) and quantitative evaluations: Kotlow's free tongue measurement (normal $\geq 16 \mathrm{~mm}$ ) [23], Mouth Opening with Tongue Tip to incisive papilla (MOTTIP, normal $\geq 23 \mathrm{~mm}$ ) [24], Maximal Intercisal Mouth Opening (MIO normal $\geq 35 \mathrm{~mm}$ ) [25]. The approach of treatment is multidisciplinary, based on the alterations which are present. Oral myofunctional therapy is sufficient in borderline cases; however, surgery is indispensable under the other mentioned pathological circumstances. There are three possible surgical procedures to resolve a pathological lingual frenulum: traditional with scalpel, electrosurgery, and laser surgery. The latter presents several advantages [26]: disinfection, precise incisions, minimal damage to adjacent tissues, hemostatic effect, better postoperative progress [27], no need for sutures, and a reduction of the dose of local anesthetic $[27,28]$. These advantages are more important for pediatric patients than for adults, since children experience increased anxiety due to the surgical intervention experience [29].

In the literature, different studies have demonstrated the benefits of the use of lasers, but most of them were not randomized, high-quality studies [30], nor did they evaluate the quantitative postoperative improvement of the frenulum. Therefore, the aim of our clinical, randomized, doubleblind study was to determine the increment (in millimeters) and postsurgical qualitative improvement following the use of diode laser technology, through the application of qualitative scales and the Quick Tongue Tie Assessment Tool ${ }^{\circledR}$.

\section{Materials and Methods}

This study conforms to the European Union rules on good clinical practice, according to the declaration of Helsinki. A clinical, randomized, double-blind study was conducted to evaluate the quantitative and qualitative increment of the aforementioned parameters (Kotlow, MOTTIP, MIO, Protrusion) post frenulectomy with diode-laser technology. One hundred and twenty-five patients were recruited by the Maxillo-Facial Department, Pediatric Dentistry, University of Rome "Sapienza", from May 2018 to August 2019; 66 male (52.6\%) and 59 female (47.4\%); with an average age of 8 years $(\mathrm{M}=$ 8.37 ; DS $=2.31$ ). The inclusion criteria were: between $4-14$ years of age, pathological lingual frenulum (Kotlow with a length $\leq 16 \mathrm{~mm}$ and lack of tongue functionality), no previous frenulectomy/frenulotomy intervention, no systemic diseases, no unhealthy habits, no temporomandibular disorders, or signed informed consent by the legal guardian of each subject. The exclusion criteria were: absolute or relative contraindication to local anesthesia, no pathological frenulum (Kotlow with a length $\geq 16 \mathrm{~mm}$ and good function of tongue), presence of systemic disease, presence of unhealthy habits, temporomandibular disorders, or failure to provide informed consent. The device used was set up to follow the protocol of study (Table 1). 
Table 1. Setting of the device.

\begin{tabular}{cc}
\hline Name & Doctor Smile ${ }^{\circledR}$ (Wiser Laser Evolution) \\
\hline Wavelength & $980 \mathrm{~nm}$ \\
Highest output power & 7- pulsed Watts \\
Modality of pulse & Variable pulse wave \\
Frequency & Up to $25 \mathrm{~Hz}$ \\
Medical class/Laser & $\mathrm{B} / 4$ \\
Tissue Optimized Pulsing & Adjustable power for every type of soft tissue \\
Diameter fiber & $300 \mu \mathrm{m}$ \\
Duration of intervention & $300 \mathrm{sec}$ \\
Number of session & Single surgery session \\
Production site & Italy-Brendola (VI)
\end{tabular}

\subsection{Dimensions of Sample and Randomization: Generation of Sequences}

The patients were randomly divided in four pre-operative groups (A, B, C, D) through an algorithm generated by a computer; a fifth group (E) was composed of case-control patients, in which subjects had a borderline pathological frenulum, and therapy was only with myofunctional exercise. In conformity with this clinical, randomized, double-blind study, neither the oral surgeon nor the patient were aware of the group to which they had been assigned. A different dental practitioner performed the follow-up for qualitative evaluations and quantitative measurements of Kotlow, MOTTIP, MIO, and distance between the tip of the protruded tongue and the incisal margin (Protrusion) in both the operating groups and the control group. The analysis of data was conducted with the statistical program SPSS ${ }^{\circledR}$ (version 24.0). An analysis of variance (ANOVA) for repeated measures was used to evaluate whether there were modifications of single parameters in the different groups of subjects. A second ANOVA was carried out among the subjects to evaluate whether there were significant increases in the different groups.

\subsection{Sample Size Calculation}

The sample size calculation was performed through G-Power analysis. The minimum number of patients was 25 for each group, with an $\alpha$ error of 0.05 and power of $80 \%$, (Table 2).

Table 2. Summary of data for each group.

\begin{tabular}{llll}
\hline & Number of Patients & Gauze & Speech Therapy \\
\hline Group A (GA) & 25 & Yes & Yes \\
Group B (GB) & 25 & No & Yes \\
Group C (GC) & 25 & Yes & No \\
Group D (GD) & 25 & No & No \\
Group E (GE) & 25 & No, Control-group & No, Control-group \\
\hline
\end{tabular}

The surgical protocol followed was:

1. One week before the operation, the oral surgeon verbally explained functional exercises to all patients and legal guardians; for oral myofunctional therapy, the protocol explained in a study of Amat et al. [22] was followed

2. The oral surgeon performed the operation with the use of local anesthesia, stabilizing the tongue using hemostatic forceps and cutting with a diode laser, the settings of which are provided above. In groups A and C, a sterile iodoformic gauze (length $3 \mathrm{~cm}$, rolled up in a rotund way) was affixed with a suture $\left(4.0\right.$ Vicryl $\left.{ }^{\circledR}\right)$; the gauze was added to determine whether it it could provide a reduction in reattachment, i.e., minor relapse. It was removed by the oral surgeon four days after the operation.

3. In groups A and B, speech therapy was prescribed (with the same therapist) in addition to functional exercise [22]. While in the latter case, all the exercises cause simultaneous contractions of 
the muscles both of the tongue and perioral area, the role of the therapist, instead, was to individualize the exercises for each patient, starting to mobilize the tongue and then adding movements for the perioral muscles. As for the gauze, the therapy was added to determine whether it could lead to a reduction in reattachment, i.e., a minor relapse.

4. Each patient received a diary which contained a representation of the prescribed myofunctional exercises [22] and the numerical rating scale (NRS) necessary to evaluate the pain $24 \mathrm{~h}, 48 \mathrm{~h}, 72 \mathrm{~h}$, 14 days and 28 days after the operation. The patients of the control group had a diary with only an explanation of the functional exercises to be followed three times a day for one month.

All patients were included in follow-up programs (T0, T1, T2, T3, and T4, with 7 days of difference amongst them) to evaluate the aforementioned parameters with a disposable instrument, the Quick Tongue Tie Assessment Tool ${ }^{\circledR}$ (QTT). In order not to modify the repeated measurements, the patients were positioned with a natural head posture and with the eyes focused on a point in the distance at eye level.

\section{Results}

The results, expressed in $\mathrm{mm}$ (Table 3), obtained from all the dependent variables from T0 to T4 (for each $p<0.001$ ) are shown below.

Table 3. Quantitative results of parameters and NRS evaluation.

\begin{tabular}{lccccccccccc}
\hline & Group & \multicolumn{2}{c}{ Kotlow } & \multicolumn{2}{c}{ MOTTIP } & \multicolumn{2}{c}{ MIO } & \multicolumn{2}{c}{ Protrusion } & \multicolumn{2}{c}{ NRS } \\
& & T0 & T4 & T0 & T4 & T0 & T4 & T0 & T4 & 24 H & 30 D \\
\hline A & Average & 17.5 & 26.5 & 19.7 & 23 & 38 & 44.1 & 17.6 & 21 & 6.8 & 0 \\
& Std deviation & 2.26 & 3.9 & 5.6 & 4.52 & 5.6 & 4.9 & 2.7 & 5.8 & 1.9 & 0 \\
& Minimum & 15 & 20 & 15 & 17 & 35 & 37 & 15 & 14 & 4 & 0 \\
& Maximum & 20 & 32 & 31 & 30 & 50 & 50 & 22 & 32 & 10 & 0 \\
\hline B & Average & 14 & 24.8 & 15.1 & 23.5 & 39.6 & 43.5 & 14 & 21 & 2.9 & 0 \\
& Std deviation & 2.9 & 3.4 & 6.7 & 4.2 & 4.6 & 4.0 & 5.1 & 5.4 & 2.1 & 0 \\
& Minimum & 10 & 21 & 5 & 15 & 35 & 40 & 7 & 15 & 0 & 0 \\
& Maximum & 18 & 30 & 25 & 30 & 50 & 50 & 21 & 30 & 6 & 0 \\
\hline C & Average & 15.3 & 23.7 & 14.3 & 23.7 & 36 & 40 & 16 & 21.3 & 7.1 & 0 \\
& Std deviation & 4.27 & 3.90 & 5.6 & 6.6 & 4.5 & 4.2 & 5.8 & 6.7 & 2.6 & 0 \\
& Minimum & 10 & 17 & 9 & 15 & 27 & 30 & 4.2 & 6.5 & 2 & 0 \\
& Maximum & 20 & 28 & 25 & 35 & 40 & 43 & 25 & 30 & 10 & 0 \\
\hline D & Average & 16.3 & 27.5 & 17.9 & 29 & 39.2 & 45.7 & 18.4 & 23.3 & 6.0 & 0 \\
& Std deviation & 4.0 & 4.3 & 6.6 & 6.9 & 3.9 & 5.7 & 4.2 & 6.5 & 2.8 & 1.2 \\
& Minimum & 10 & 20 & 10 & 17 & 35 & 40 & 12 & 16 & 2 & 0 \\
& Maximum & 21 & 33 & 25 & 35 & 45 & 55 & 25 & 35 & 9 & 3 \\
\hline E & Average & 20.9 & 25.9 & 22.6 & 26.1 & 40.3 & 44.3 & 20.4 & 23.5 & & \\
& Std deviation & 3.6 & 2.6 & 5.7 & 5.5 & 5.4 & 4.6 & 4.3 & 4.1 & control.g & control.g \\
& Minimum & 15 & 23 & 15 & 15 & 35 & 40 & 14 & 17 & & \\
& Maximum & 30 & 31 & 32 & 36 & 45 & 55 & 25 & 30 & & \\
\hline
\end{tabular}

Viewing the results in a bullet-point list, we observe the following:

Time 0: day of intervention.

Time 1: there were not any significant differences in Kotlow. MOTTIP had a better trend of growth in GD than in GC; there was no a significant difference in the other groups. MIO in GB, GD and GE obtained a score superior to GC; GA is an intermediate position. The value of Protrusion was greater in GE than in the other groups.

Time 2: there were no significant differences in Kotlow. MOTTIP had a trend of growth better in GD and GE compared to GB and GA; there was no significant difference in the other groups. MIO in 
GC obtained a lower score than the other groups. The value of Protrusion was greater in GD and GE in comparison to the other groups.

Time 3: the scores of Kotlow and MOTTIP were superior in GD than in the other groups. MIO in GC obtained a lower score than the other groups. In protrusion, there was no significant difference.

Time 4: the score of Kotlow was superior in GD compared to GC; there was no significant difference in the other groups. MOTTIP had a better trend of growth in GD than in the other groups. MIO in GC obtained a lower score than the other groups. There was no significant difference in Protrusion.

From the beginning of treatment (Figures 1 and 2) to the end (Figures 2 and 3): for Kotlow, the increase was more or less the same in all the groups, except for the control group; for MOTTIP, the largest increases were observed in GB, GC, and GD; for MIO, the increase was significant in all groups except for GC; the increase of Protrusion was similar in all groups. The perception of pain at T0 was lower in GB than in the other groups; at T4, the score was 0 in all the groups. According to the results, it was possible to understand how the presence of gauze and speech therapy did not change the final outcome; therefore, the application of gauze to avoid a possible relapse is not recommended, and speech therapy is advisable only when the child shows unhealthy habits or language problems. The oral myofunction exercises (according the aforementioned protocol [22]) is essential to achieve a full upswing of lingual functionality.
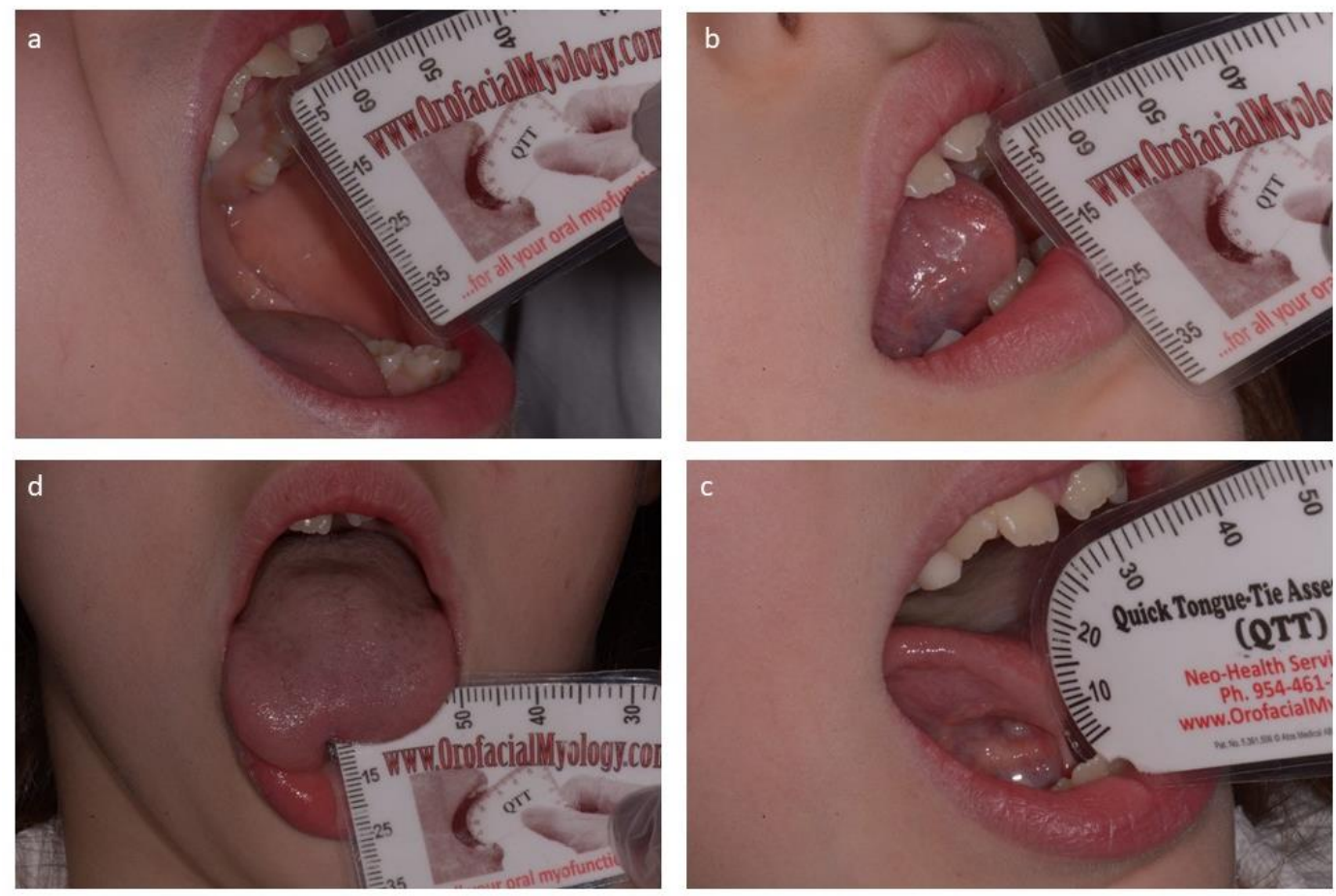

Figure 1. Quantitative evaluation at t0: (a) (MAB), (b) (MIO), (c) (MOTTIP), (d) (PROTRUSIONE).
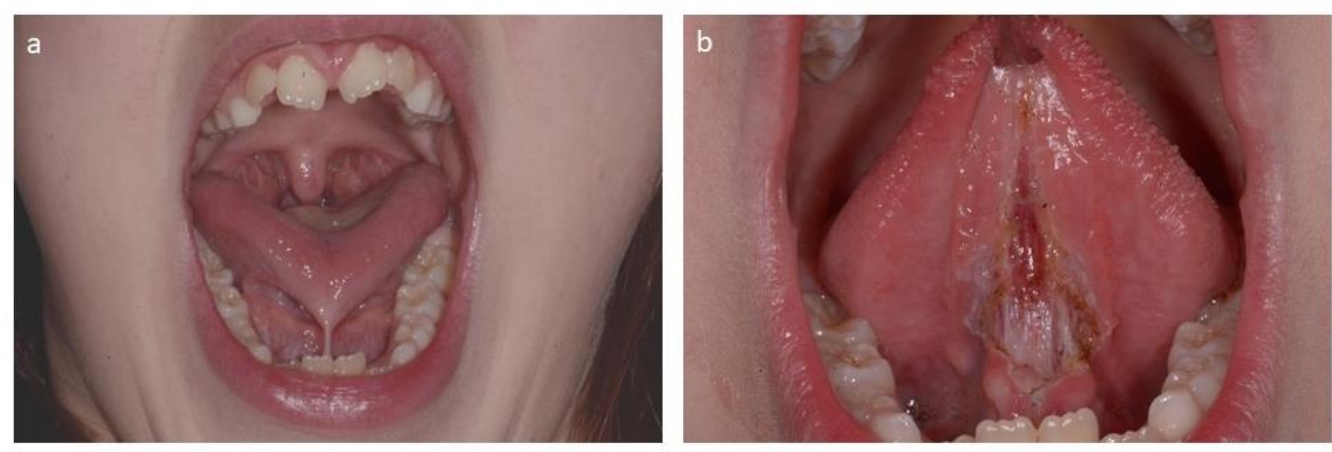

Figure 2. Clinical evaluation: (a) (preoperative), (b) (postoperative). 

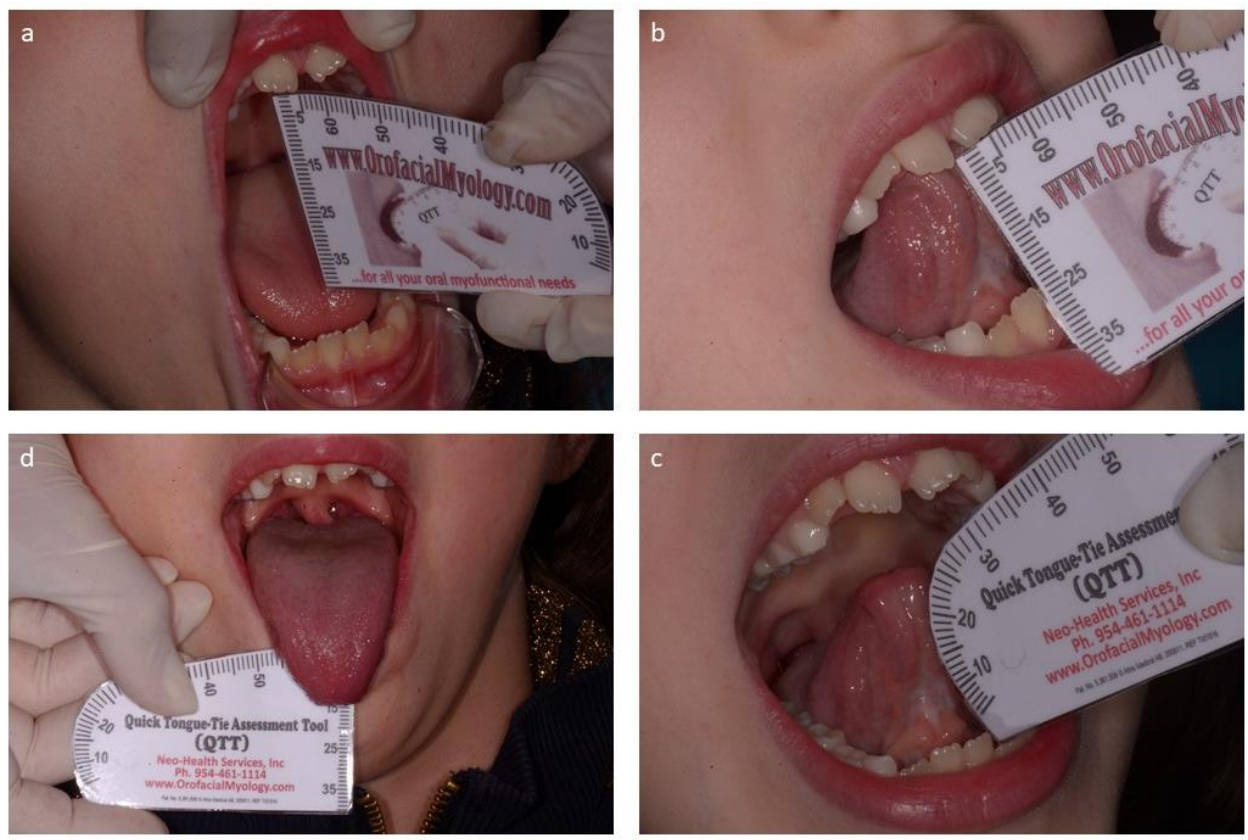

Figure 3. Quantitative evaluation t4: (a) (MAB), (b) (MIO), (c) (MOTTIP), (d) (PROTRUSIONE).

\section{Clinical Case}

\section{Discussion}

Through the use of this protocol, the efficacy of the diode laser technique was demonstrated for lingual frenulectomies in pediatric patients; this technique makes it possible to quantitatively increase the aforementioned parameters until physiological values are reached, bringing about the acquisition of full lingual functionality with minor anxiety and pain. Several studies have performed millimetrical evaluations to determine the best methods for the correct diagnosis of ankyloglossia [23-25], but none of them has considered the different pre- and post- operative increases, nor have they examined the use of different type of lasers. Marchesan et al. presented a quantitative method to classify the pathological lingual frenulum with no consideration of improvement after surgical intervention [31]. Yoon et al. [25] employed the same millimetrical device used in our study $(\text { QTT })^{\circledR}$, but the aim of their study was to validate millimetrical parameters as an initial screening tool to asses for restrictions in tongue mobility. However, in our study, millimetrical evaluation was essential not only for the screening, but also to verify the efficacy of diode laser technology in the improvement of tongue mobility after surgical intervention.

In this way, an unexpected result of this study was the observed continuous improvement in the first month after surgery; our analysis demonstrates how the increase from T0 to T1, T2, T3 and $\mathrm{T} 4$ is gradual in relation to the better functionality of the tongue. A similar correlation was noted in a study by Ghaheri BA et al. [32], in which enhancement after frenulectomy occurred early (1 week postoperatively), and continued to improve one month thereafter; both infants with classic anterior tongue-tie and less obvious posterior tongue-tie showed improvements, proving the superiority of the laser-technique. Nagate Raghavendra Reddy et al. [33] reported on five clinical cases of short lingual frenulum; three of them were treated with electrocautery therapy, one with a diode laser and the last one with a traditional surgical technique (scalpel 15c). After follow-ups at 7 and 30 days, a better management of tissues was observed in cases treated with laser or electrocautery than with traditional surgical techniques. In the latter case, the pain and swelling were also superior. This study observed how the use of laser for the treatment of frenulectomy can be considered safe and reliable; reduced pain and better function of the tongue are guaranteed after surgery. Derikvand $\mathrm{N}$ et al. [34] also explained several advantages of laser technology, demonstrating how it supports 
healing and reduces postoperative complications. Barot VJ et al. [35] reported very positive results after a frenulectomy with laser technology (Wavelength: $810 \mathrm{~nm}$, Diameter fiber: $200 \mu \mathrm{m}$, used in direct contact with the tissue, Power $2 \mathrm{~W}$, continuous modality and focused ray). Through this protocol, the authors achieved complete healing, a $>16-\mathrm{mm}$ increase of tongue mobility, and an improvement of speech after therapy. Laser-assisted lingual frenectomies are the simplest, safest, and least traumatic of all the treatment modalities available, with the most promising results in minimally invasive dentistry. With the use of diode lasers, it is also possible to obtain a reduction in operative times and gain easier access to the surgical site; indeed, the lack of traditional surgical instruments and the localized cauterization allow bloodless surgery. Marina Azevedo Junqueira et al. [36] confirmed how it is possible to reach the bottom of the lingual muscle with the use of a laser; they affirmed the superiority of the technique, compared to other approaches. This technology is more acceptable for children, yielding with shorter operative times, hemostasis, and no need for local anesthesia.

Regarding orofacial myofunctional disorders, it was demonstrated how the correct function of the tongue is essential for the neuromuscular harmony of the whole maxillo-facial area [37]. A short lingual frenulum has a critical impact on the development of the orofacial complex [38]; for this reason, frenulectomies associated with the orofacial myofunctional therapy (OMT) do not allow the tissue to reattach postoperatively [39]. The value of OMT was also demonstrated in a study by Tecco et al. [40]; the study showed the improvement in the oral muscles in subjects following an OMT after a lingual frenulectomy using electromyography. It is recommended that pediatric patients start myofacial rehabilitation before the surgical operation (i.e., one week before); in this way, they can learn to perform the exercises without pain. Our study applied orofacial myofunctional therapy based upon a protocol described by Amat et al. [22]. The use of the NRS pain scale allows for easier identification of the different intensities of pain compared to other scales, that have the tendency to categorize pain as simply none, light, moderate or severe. A study by Pagé MG et al. [41] showed that with the NRS, it's possible to represent the continuity of pain, which is appropriate for children between 8 and 18 years of age. The authors underlined how important it is that the child or teenager understand the correct use of this scale in order to assign a number to the intensity of their pain. However, due to the subjectivity of pain, there is no tool which gives a precise value; for this reason further studies are required to find more a precise method

In accordance with several different articles underlining the advantages of the use of lasers, our study demonstrated how after a frenulectomy, and following the oral myofunctional protocol, there was an approximate increase of $10 \mathrm{~mm}$ (Kotlow and Protrusion) and $5 \mathrm{~mm}$ (MIO and MOTTIP). Using the Quick Tongue Tie Assessment Tool ${ }^{\circledR}$, a complete improvement of physiological values was observed in all groups. We also demonstrated how the use of a gauze and speech therapy is not essential, except, in the latter case, when the child has unhealthy habits or speech problems.

\section{Conclusions}

The conclusions of this study support the thesis that laser technology, together with oral myofunctional therapy, is an efficient and innovative treatment for frenulectomy. In fact, the observed millimetrical and functional postoperative increases were enough to normalize the function of the lingual organ. Definitely, new studies will be needed with larger numbers of subjects to obtain more sensitive and specific data concerning the typology of the protocol used.

\section{Limitations of the Study}

The evaluation of pain is extremely subjective.

Inconsistent levels of compliance by the patients could have influenced the improvements of the parameters unevenly.

Author Contributions: Conceptualization, G.L.S., F.Z., M.F.; methodology, G.L.S., F.Z., M.F.; software M.G.; validation, G.L.S., A.P., G.P.; formal analysis, F.Z., M.F.; investigation, G.L.S., F.Z., M.F.; resources, A.P., M.G.; data curation, G.L.S., F.Z., M.F.; writing—original draft preparation, F.Z., M.F.; writing—review and editing, G.L.S., 
G.P., A.P.; visualization, G.P., M.G.; supervision G.L.S., and A.P.; project administration, G.L.S., A.P. All authors have read and agreed to the published version of the manuscript.

Funding: The work was supported by the Department of Oral and Maxillo-Facial Science, Pediatric Dentistry Unit, Policlinico Umberto I, Rome, Italy.

Ethical Approval: All procedures performed in studies involving human participants were carried out in accordance with the ethical standards of the institutional and/or national research committee and with the 1964 Helsinki Declaration and its later amendments or comparable ethical standards.

Conflicts of Interest: The authors certify that there is no conflict of interest with any financial organization regarding the material discussed in the manuscript.

\section{References}

1. Winning, T.; Townsend, G. Oral mucosal embryology and histology. Clin. Dermatol. 2000, 18, 499-511. [CrossRef]

2. Sinnatamby, C.S. Last's Anatomy: Regional and Applied Edinburgh; Churchill Livingstone/Elsevier: New York, NY, USA, 2011.

3. Standring, S. Gray's Anatomy: The Anatomical Basis of Clinical Practice; Elsevier Limited: Philadelphia, PA, USA, 2016.

4. Mills, N.; Keough, N.; Geddes, D.T.; Pransky, S.M.; Mirjalili, S.A. Defining the anatomy of the neonatal lingual frenulum. Clin. Anat. 2019, 32, 824-835. [CrossRef]

5. Mills, N.; Pransky, S.M.; Geddes, D.T.; Mirjalili, S.A. What is a tongue tie? Defining the anatomy of the in-situ lingual frenulum. Clin. Anat. 2019, 32, 749-761. [CrossRef] [PubMed]

6. Olivi, G.; Signore, A.; Olivi, M.; Genovese, M.D. Lingual frenectomy: Functional evaluation and new therapeutical approach. Eur. J. Pediatr. Dent. 2012, 13, 101-106.

7. Ballard, J.L.; Auer, C.E.; Khoury, J.C. Ankyloglossia: Assessment, Incidence, and Effect of Frenuloplasty on the Breastfeeding. Pediatrics 2002, 110, e63. [CrossRef] [PubMed]

8. Illing, S.; Minnee, M.; Wheeler, J.; Illing, L. The value of frenotomy for ankyloglossia from a parental perspective. N. Z. Med. J. 2019, 132, 70-81.

9. Queiroz, M.I. Lingual frenulum: Classification and speech interference. Int. J. Orofacial. Myol. 2004, 30, 31-38.

10. Messner, A.H.; Lalakea, M.L. The effect of ankyloglossia on speech in children. Otolaryngol. Head Neck Surg. 2002, 127, 539-545. [CrossRef]

11. Chinnadurai, S.; Francis, D.O.; Epstein, R.A.; Morad, A.; Kohanim, S.; McPheeters, M. Treatment of ankyloglossia for reasons other than breastfeeding: A systematic review. Pediatrics 2015, 135, e1467-74. [CrossRef]

12. Lalakea, M.L.; Messner, A.H. Ankyloglossia: Does it matter? Pediatr. Clin. N. Am. 2003, 50, $381-397$. [CrossRef]

13. Ierardo, G.; Luzzi, V.; Sfasciotti, G.L.; Nardacci, G.; Polimeni, A.; Vozza, I. Using of modified rapid palate expander with miniscrews in a patient affected by ectodermic dysplasia. Clin. Ther. 2019, 170, e168-e173.

14. Guilleminault, C.; Huseni, S.; Lo, L. A frequent phenotype for paediatric sleep apnoea: Short lingual frenulum. ERJ Open Res. 2016, 2, 00043-2016. [CrossRef] [PubMed]

15. Meenakshi, S.; Jagannathan, N. Assessment of Lingual Frenulum Lengths in Skeletal Malocclusion. J. Clin. Diagn. Res. 2014, 8, 202-204. [PubMed]

16. Di Carlo, G.; Saccucci, M.; Luzzi, V.; Ierardo, G.; Vozza, I.; Sfasciotti, G.L.; Polimeni, A. Prevalence of maxillary canine impaction in skeletal Class III malocclusions compared to Class I malocclusions. J. Clin. Exp. Dent. 2019, 11, e264-e268. [CrossRef] [PubMed]

17. Ata, N.; Alataş, N.; Yılmaz, E.; Adam, A.B.; Gezgin, B. The Relationship of Ankyloglossia with Gender in Children and the Ideal Timing of Surgery in Ankyloglossia. Ear Nose Throat J. 2019, 26, 45561319867666. [CrossRef]

18. Renfrew, M.J.; Dyson, L.; Wallace, L. The Effectiveness of Public Health Interventions to Promote the Duration of Breastfeeding: Systematic Reviews of the Evidence; National Institute for Health and Clinical Excellence: London, UK, 2005. 
19. Segal, L.M.; Stephenson, R.; Dawes, M.; Feldman, P. Prevalence, diagnosis, and treatment of ankyloglossia: Methodologic review. Can. Fam. Physician 2007, 53, 1027-1033.

20. Amir, L.H.; James, J.P.; Donath, S.M. Reliability of the hazelbaker assessment tool for lingual frenulum function. Int. Breastfeed J. 2006, 1, 3. [CrossRef]

21. Ingram, J.; Johnson, D.; Copeland, M. The development of a tongue assessment tool to assist with tongue-tie identification. Arch. Dis. Child Fetal. Neonatal. Ed. 2015, 100, F344-F348. [CrossRef]

22. Ferrés-Amat, E.; Pastor-Vera, T.; Ferrés-Amat, E.; Mareque-Bueno, J.; Prats-Armengol, J.; Ferrés-Padró, E. Multidisciplinary management of ankyloglossia in childhood. Treatment of 101 cases. A protocol. Med. Oral Patol. Oral Cir. Bucal. 2016, 21, e39-e47. [CrossRef]

23. Kotlow, L.A. Ankyloglossia (tongue-tie): A diagnostic and treatment quandary. Quintessence Int. 1999, $30,4$.

24. Ruffoli, R.; Giambelluca, M.A.; Scavuzzo, M.C.; Bonfigli, D.; Cristofani, R.; Gabriele, M.; Giuca, M.R.; Giannessi, F. Ankyloglossia: A morphofunctional investigation in children. Oral Dis. 2005, 11, 170-174. [CrossRef] [PubMed]

25. Yoon, A.; Zaghi, S.; Weitzman, R.; Ha, S.; Law, C.S.; Guilleminault, C.; Liu, S.Y.C. Toward a functional definition of ankyloglossia: Validating current grading scales for lingual frenulum length and tongue mobility in 1052 subjects. Sleep Breath. 2017, 2, 767-775. [CrossRef] [PubMed]

26. Vozza, I.; Mari, D.; Pacifici, E.; Luzzi, V.; Ierardo, G.; Sfasciotti, G.L.; Polimeni, A. Pediatric patients tolerance: A comparative study about using of Er: YAG laser and self-adhesive flowable composite for treatment of primary decayed teeth. Ann. Stomatol. (Roma) 2016, 7, 24-28. [CrossRef]

27. Medeiros, J.R.; Gueiros, L.A.; Silva, I.H. Labial frenectomy with Nd: YAG. Laser and conventional surgery: A comparative study. Lasers Med. Sci. 2015, 30, 851-856.

28. Hanna, R.; Parker, S. The advantages of carbon dioxide laser applications in paediatric oral surgery. A prospective cohort study. Lasers Med. Sci. 2016, 31, 1527-1536. [CrossRef]

29. Pié-Sánchez, J.; España-Tost, A.J.; Arnabat-Domínguez, J.; Gay-Escoda, C. Comparative study of upper lip frenectomy with the $\mathrm{CO}_{2}$ laser versus the Er, Cr: YSGG laser. Med. Oral Patol. Oral Cir. Bucal. 2012, 17, e228-e232.

30. Garrocho-Rangel, A.; Herrera-Badillo, D.; Pérez-Alfaro, I.; Fierro-Serna, V.; Pozos-Guillén, A. Treatment of ankyloglossia with dental laser in paediatric patients: Scoping review and a case report. Eur. J. Paediatr. Dent. 2019, 20, 155-163.

31. Marchesan, I.Q. Lingual frenulum: Quantitative evaluation proposal. Int. J. Orofac. Myol. 2005, 31, 39-48.

32. Ghaheri, B.A.; Cole, M.; Fausel, S.C.; Chuop, M.; Mace, J.C. Breastfeeding improvement following tongue-tie and lip-tie release: A prospective cohort study. Laryngoscope 2017, 127, 1217-81223. [CrossRef]

33. Reddy, N.R.; Marudhappan, Y.; Devi, R.; Narang, S. Clipping the tongue tie. J. Indian Soc. Periodontol. 2014, 18, 395-398. [CrossRef]

34. Derikvand, N.; Chinipardaz, Z.; Ghasemi, S.; Chiniforush, N. The Versatility of 980 nm Diode Laser in Dentistry: A Case Series. J. Lasers Med. Sci. 2016, 7, 205-208. [CrossRef] [PubMed]

35. Varshal, J.B.; Vishnoi, S.L.; Chandran, S.; Bakutra, G.V. Laser: The torch of freedom for ankyloglossia. Indian J. Plast. Surg. 2014, 47, 418-422.

36. Junqueira, M.A.; Cunha, N.N.; Costa e Silva, L.L.; Araújo, L.B.; Moretti, A.B.; Couto Filho, C.E.; Sakai, V.T. Surgical techniques for the treatment of ankyloglossia in children: A case series. J. Appl. Oral Sci. 2014, 22, 241-248. [CrossRef]

37. Felício, C.M.; Ferreira, C.L. Protocol of orofacial myofunctional evaluation with scores. Int. J. Pediatr. Otorhinolaryngol. 2008, 72, 367-375. [CrossRef]

38. Romero, C.C.; Scavone-Junior, H.; Garib, D.G.; Cotrim-Ferreira, F.A.; Ferreira, R.I. Breastfeeding and non-nutritive sucking patterns related to the prevalence of anterior open bite in primary dentition. J. Appl. Oral Sci. 2011, 19, 161-168. [CrossRef] [PubMed]

39. Moeller, J.L. Orofacial myofunctional therapy why not? Editorial. Cranio 2012, 30, 5-7. [CrossRef] 
40. Tecco, S.; Baldini, A.; Mummolo, S.; Marchetti, E.; Giuca, M.R.; Marzo, G.; Gherlone, E.F. Frenulectomy of the tongue and the influence of rehabilitation exercises on the sEMG activity of masticatory muscles. $J$. Electromyogr. Kinesiol. 2015, 25, 619-628. [CrossRef]

41. Pagé, M.G.; Katz, J.; Stinson, J.; Isaac, L.; Martin-Pichora, A.L.; Campbell, F. Validation of the numerical rating scale for pain intensity and unpleasantness in pediatric acute postoperative pain: Sensitivity to change over time. J. Pain 2012, 13, 359-369. [CrossRef]

(C) 2020 by the authors. Licensee MDPI, Basel, Switzerland. This article is an open access article distributed under the terms and conditions of the Creative Commons Attribution (CC BY) license (http://creativecommons.org/licenses/by/4.0/). 